\title{
Application of the island-genetic algorithm to optimal impact resistance design of a RC slab
}

\author{
A. Miyamoto \& H. Emoto \\ Department of Computer and Systems Engineering, \\ Yamaguchi University, Japan
}

\begin{abstract}
When seeking optimal parameters by numerical analysis in performance-based design, the number of combinations may increase to an extreme level, or objective functions or restrictions may not be accurately formulated. Then, genetic algorithms (GAs) are sometimes used. For certain problems, however, computation takes much time or no effective solutions are obtained even with the use of GAs. To compensate for such shortcomings, this study examines the applicability of island genetic algorithm (island-GA), a type of distributed genetic algorithm, to design problems. Using distributed-GA is expected to lead to efficient application of grid computing. Then, the time of computation may be reduced and networks of computers may be used effectively. The effectiveness of island-GA is verified in optimal impact resistance design for reinforced concrete slabs as an example of design problem.
\end{abstract}

\section{Introduction}

In structural design, the finite element method (FEM) and other numerical analysis techniques have been used widely and design proposals based on such analysis methods have been examined on a daily basis. In engineering design, however, numerous parameters exist and a wide variety of restrictions should be taken into consideration. Using numerical analysis techniques including the FEM for checking design proposals therefore involves the handling of a large number of combinations of design parameters. Then, obtaining solutions within a practical time frame may be sometimes difficult. One of the effective solutions to such a problem is genetic algorithm (GA), which simulates the hereditary and evolutionary processes of species on computers. GA has been applied to 
numerous design problems and proved to be effective. Sugimoto et al. [1] formulated the design of temporary steel pile sheeting as a multi-purpose discrete optimization problem and applied GA to the problem. Sugimoto et al. [2] also added growth operators to GA to increase the reliability of structural optimization. Katsuki et al. [3] examined the applicability of GA to interactive truss structure optimization problems. The authors [4] adopted GA for solving a problem of external cable strengthening design and confirmed the effectiveness of GA.

In numerous actual design problems, highly practicable multiple suboptimal solutions are preferable to a globally exact optimal solution from a practical viewpoint. For example, there is a limit to the incorporation of all the ideas of the designer into objective functions and some factors cannot be reflected in design by any means. In some cases, an exact optimal solution may be of no significance. Then, practicable multiple solutions are more effective.

When supporting design work based on the FEM, when handling an unsteady or nonlinear problem in particular, computation takes much time even with the use of GA for optimization. To solve such a problem, grid computing with multiple computers connected to one another via a network [5] has recently been gathering attention. As an example, educational personal computers constituting a network were used for auto crash analysis while they were not in operation during the night in a joint study by Hiroshima University, MAZDA Motor Corporation and FUJITSU Corporation [6].

GAs possess parallelism, in which individuals evolve independent of one another. GAs therefore have a potential for making efficient parallel computation by using an appropriate algorithm.

In order to obtain multiple highly practicable suboptimal solutions in a practical computation time, this study used island genetic algorithm (island-GA), one of distributed-GAs, for optimal design of reinforced concrete (RC) slabs subjected to impact loads. Island-GA is expected to contribute to faster computation and effective use of computer networks through grid computing. The study also proposed and verified the effectiveness of migration methods in island-GA that enable the search of practicable multiple solutions required for design.

\section{Outline of island-GA and proposal of migration methods}

\subsection{Outline of island-GA}

Island genetic algorithm (island-GA) [7] is one of the distributed-GA models. GA is applied to separate subpopulations in a population (Figure 1).

The island model originated from multiple sources. One is based on the concepts of habitat isolation and specialization. These concepts explain that "individuals evolve differently in geographically isolated environments such as islands and mountain villages according to the characteristics of the environment". Specifically, each subpopulation maximizes an evaluation index independently. Another origin of the island model is based on the principles of 
specialization in different areas and stable equilibrium. Specialization in different areas means that even offspring from a common ancestor perform different evolutionary processes due to the difference of environment if they are geographically isolated from one another. Stable equilibrium refers to a state in which individuals tend to keep staying in a stable environment once they settle in it. Based on the principles, each subpopulation undergoes alternation of generations until an equilibrium is reached and once a stable state is reached, each subpopulation replaces some individuals with those in a neighboring subpopulation to change the environment.

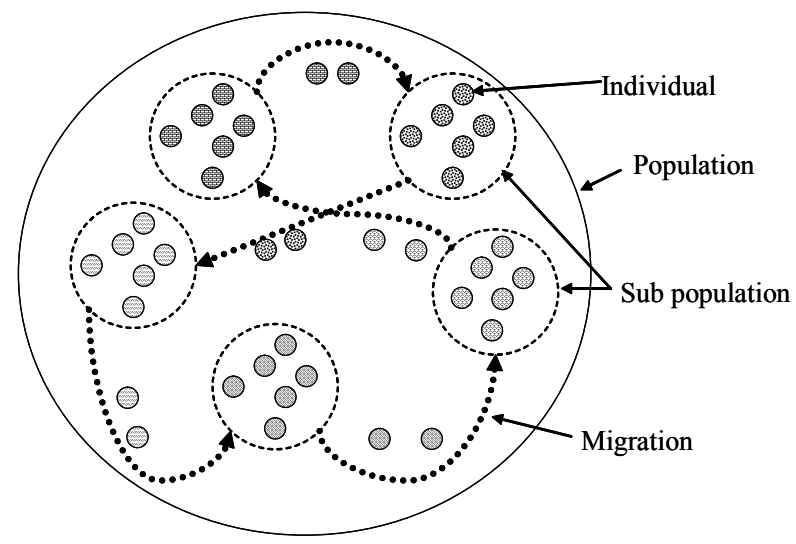

Figure 1: $\quad$ Concept of island model.

\subsection{Processing procedure in island-GA}

The island-GA has more steps than GA, step 3 "partition of population into subpopulations" and step 4 "migration" (see Figure 2). In the step of population partition, the population is partitioned into subpopulations (islands). Genetic operator takes place independently in each subpopulation. Then, GA parameters are set for each subpopulation. Parameters common to all the subpopulations are considered to be "homogeneous" and those that vary from subpopulation to subpopulation are regarded as heterogeneous parameters.

In the step of migration, best individuals are exchanged between subpopulations. The relationship among subpopulations comes in different types such as line-shaped, ring-shaped or random-type [8]. The timing of exchange of individuals needs to be set. If the interval of migration is fixed, the timing is expressed by the interval of migration. Migration with a fixed interval is referred to as the "synchronous migration". The number of migrants is controlled based on the rate of migration. Some works have reported that island-GAs produce better solutions than single-population GAs owing to the effectiveness of migration $[9,10]$. 


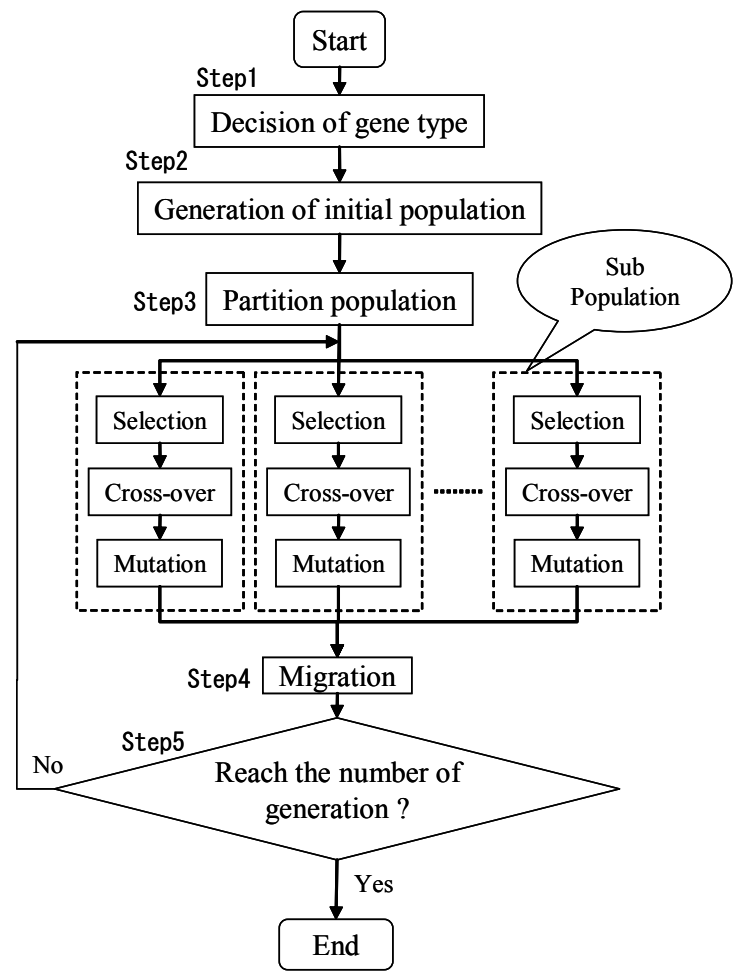

Figure 2: $\quad$ Processing steps in island model.

\subsection{Proposal of migration methods using diversity index}

Synchronous migration is generally carried out in numerous cases. In synchronous migration, individuals are exchanged mechanically between subpopulations regardless of the progress of search in subpopulations. Migration means the movement of individuals from one subpopulation to another for certain purposes. And migration occurs irregularly.

A method is proposed for evaluating the progress of search in a subpopulation and performing migration. Indices for evaluating the progress of search include the mean fitness, highest fitness and index of diversity, which is an index for assessing diversity [11]. According to the basic principle of island-GA, a species (subpopulation) performs migration when the number of individuals with the same characteristics increases extraordinarily in a subpopulation. In this study, therefore, migration is performed based on the index of diversity of individuals in the subpopulation.

The method for calculating the index of diversity is described below (see Figure 3): Suppose that a generation consists of $N$ individuals with $M$ genes each and that there are $S$ alleles that individuals can have. Then, information entropy $H_{j}(N)$ for individual's locus $j$ is expressed by 


$$
H_{j}(N)=\sum_{i=1}^{S}\left(-p_{i j} \log p_{i j}\right)
$$

where, $p_{i j}$ is the possibility of $i$ th allele appearing in locus $j$, which is expressed by

$$
p_{i j}=\text { Total number of } i \text { th alleles appearing in locus } j / N
$$

Then, mean information entropy for diversity index $H(N)$ is expressed by

$$
H(N)=\frac{1}{M} \sum_{j=1}^{M} H_{j}(N)
$$

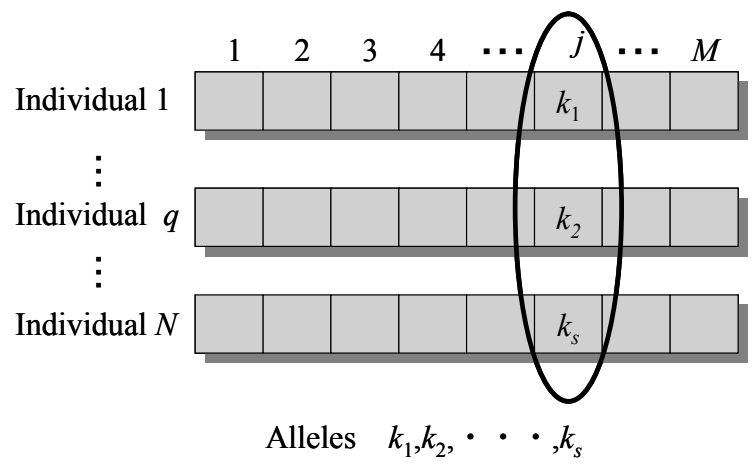

Figure 3: Concept of diversity.

Diversity is therefore measured in terms of the index of diversity using Eq. (3). A high index of diversity means that numerous individuals with different characteristics exist in the subpopulation, and a low index indicates that numerous identical individuals exist in the subpopulation. In this study, migration based on the index of diversity is referred to as "diverse index based" migration method.

The procedure of migration based on the index of diversity is shown in Figure 4. The index of diversity is calculated for each subpopulation. When the index of diversity drops below a designated threshold in a subpopulation, another subpopulation is selected from among those with the index of diversity exceeding the threshold and individuals with high fitness are migrated to the first subpopulation based on the ratio of migration. In this type of migration, even at the time of premature convergence in a subpopulation, diversity can be maintained through migration to another subpopulation that maintains diversity. In later generations after the progress of evolution, the index of diversity drops below a designated threshold in all of the subpopulations and migration of individuals becomes no longer possible. Then, the convergence is possible in the population. Thus, problems involved in premature convergence can be avoided and convergence in subpopulations becomes possible while keeping the index of diversion at an appropriate level. 


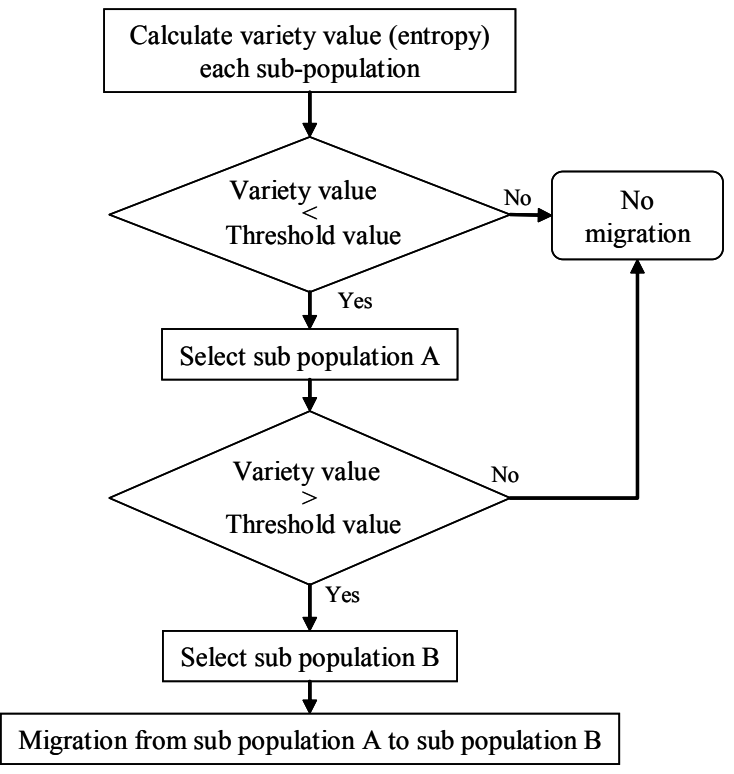

Figure 4: $\quad$ Processing steps using the index of diversity.

\section{Effectiveness of island-GA}

In order to examine its effectiveness, island-GA is compared with simple genetic algorithm (SGA), which is a genetic algorithm based on the most basic processing procedure. As a benchmark, the knapsack problem is adopted, which is a typical discretization problem.

\subsection{Knapsack problem}

The knapsack problem is defined as "selecting the set of items that is below the allowable weight $b$ for a knapsack and maximizes the total value $f$, where $a_{i}$ and $c_{i}$ are the weight and value of item $i(i=1, \ldots, \mathrm{N})$ and $b$ is the allowable weight for the knapsack. The following formulas are obtained:

$$
\begin{aligned}
& \text { maximize } \quad f=\sum_{i=1}^{N} c_{i} x_{i} \\
& \text { subject to } \quad \sum_{i=1}^{N} a_{i} x_{i} \leq b \\
& x_{i} \in\{0,1\} \quad(i=1, \cdots, N)
\end{aligned}
$$

A decision variable $x_{i}$ of 1 means that the item is put into the knapsack and $x_{i}$ of 0 indicates that the item is not in the knapsack.

In this study, the number of items $N$ and the allowable weight $b$ are set at 30 and $1.2 \mathrm{kN}(120 \mathrm{~kg})$, respectively. The total value $f$ is referred to as "fitness". 


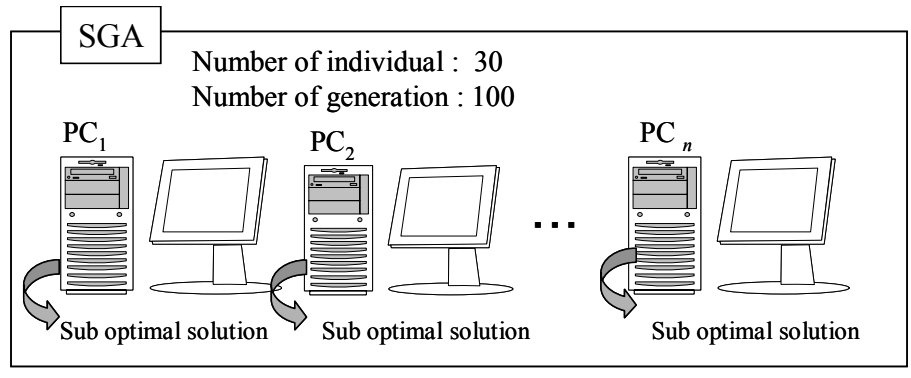

Figure 5: $\quad$ Outline of simulation by SGA.

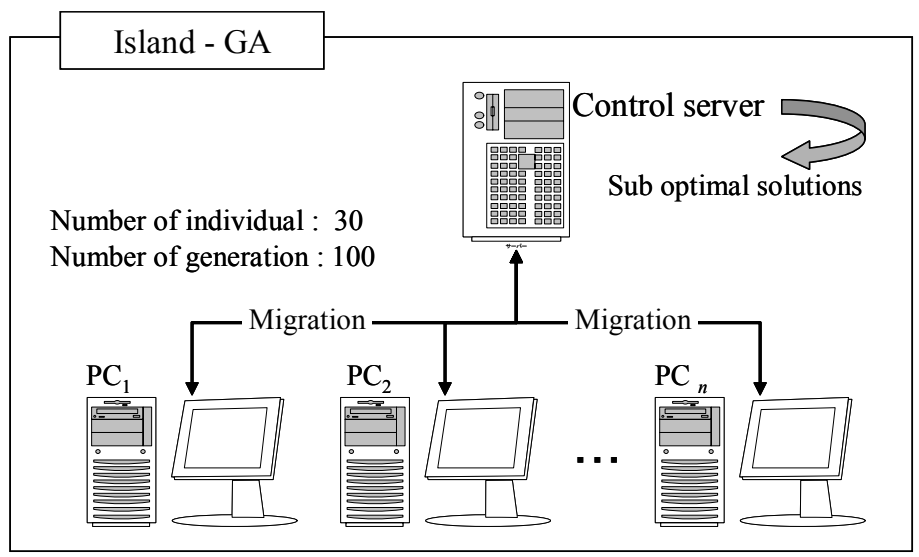

Figure 6: Outline of simulation by island GA.

Table 1: $\quad$ List of simulation conditions (GA parameters).

\begin{tabular}{|l|c|c|}
\hline & SGA & Islanad - GA \\
\hline Number of generation & \multicolumn{2}{|c|}{100} \\
\hline Number of individual & \multicolumn{2}{|c|}{20} \\
\hline Gene length & \multicolumn{2}{|c|}{30} \\
\hline Crossover rate & \multicolumn{2}{|c|}{1.00} \\
\hline Mutation rate & \multicolumn{2}{|c|}{0.02} \\
\hline Selection pressure & \multicolumn{2}{|c|}{$25 \%$} \\
\hline Method of selection & Roulette selection (elite strategy) \\
\hline Method of crossover & \multicolumn{2}{|c|}{ Two-point crossover } \\
\hline Number of sub population & \multicolumn{2}{|c|}{32} \\
\hline Number of attempts & 32 & \\
\hline
\end{tabular}




\subsection{Simulation conditions}

For comparing island-GA with multiple subpopulations and SGA using a single population, unifying computational complexity is required. In this study, a comparison is made between a case where each of multiple personal computers executes SGA (Figure 5) and a case of emulation of island-GA (Figure 6). GA parameters used in this study are listed in Table 1. Ordinary SGA adopts roulette selection, one-point crossover and mutation. The single population SGA used for comparison in this study is referred to as SGA because it uses the same selection method as ordinary SGA and adopts genetic operator with slight improvements to that of ordinary SGA. GA parameters were set by trial and error based on an engineering decision-making process.

The threshold value and migration rate for asynchronous migration based on the index of diversity were determined after verification.

\subsection{Simulation results and discussions}

\subsubsection{Threshold value and migration rate for diversity index based migration}

In order to identify the relationship between the threshold value and migration rate for diversity index based migration, a study was made in relation to the percentage of optimal solutions obtained. The threshold value determines the timing of migration and the migration rate refers to the percentage of migrants in a subpopulation.

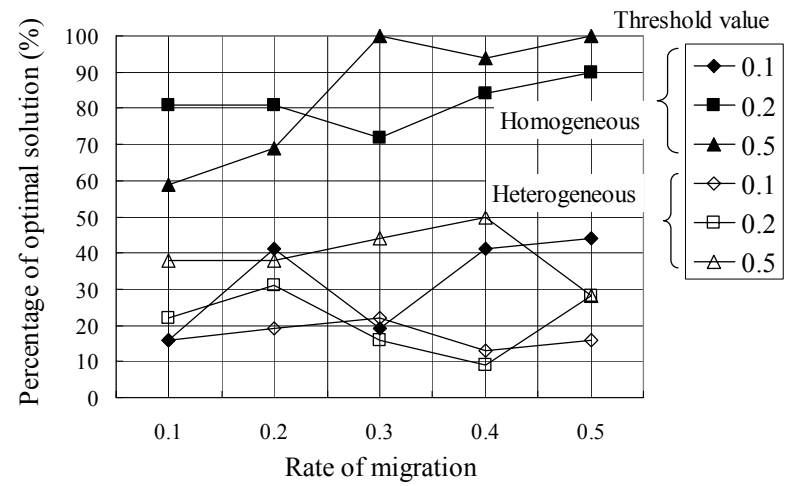

Figure 7: $\quad$ Changes in percentage of optimal solutions in relation to threshold value and rate of migration.

Migration rate was varied from 0.1 to 0.5 at 0.1 intervals. Threshold value was set at $0.1,0.2$ and 0.5 either for homogeneous or for heterogeneous model. Mutation rate was set at 0.02 for homogeneous model. Combinations of 0.02 , $0.03,0.04,0.05$ and 0.06 were used for heterogeneous model. In the homogeneous model, the percentage of optimal solutions was high at threshold values of 0.2 and 0.5 (Figure 7). This is ascribable to the convergence to an 
optimal solution for numerous individuals in the subpopulation because of a high index of diversity. The subpopulation may have evolved as if it were a single population. The higher the migration rate, the higher the possibility of an optimal solution being obtained because more individuals migrated. In the heterogeneous model or in the homogeneous model with a threshold value of 0.1 , the percentage of optimal solutions was low. This is because each subpopulation evolved independently. These are the cases effective for obtaining multiple suboptimal solutions.

Based on the above, the threshold value was set at 0.1 in this study. Migration rate was set at 0.5 to ensure the acquisition of optimal solutions.

\subsubsection{Index of diversity in subpopulation}

To evaluate diversity, distributions of suboptimal solutions obtained by running SGA multiple times in isolation and by island-GA are shown in Figure 8. Island-GA is a heterogeneous GA based on the index of diversity.

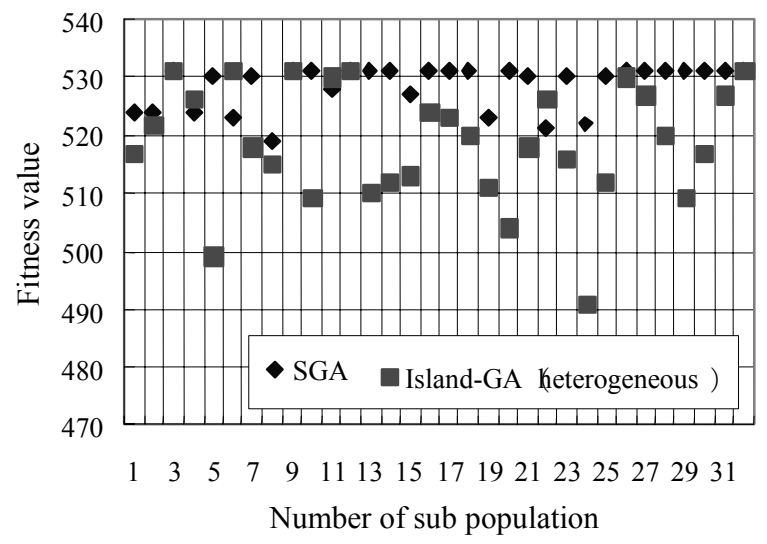

Figure 8: Distributions of highest fitness in subpopulations (distributions of highest fitness in each round of computation for SGA).

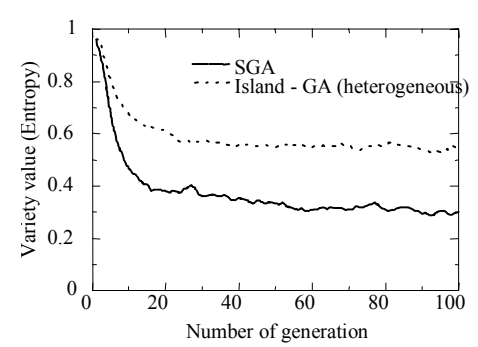

Figure 9: Changes in average index of diversity.

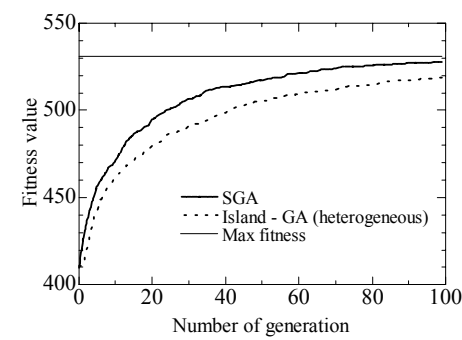

Figure 10:

Changes in highest fitness. 
Suboptimal solutions obtained by SGA are distributed between 530 and 520 around the optimal solution (Figure 8). Suboptimal solutions obtained by island-GA are distributed between 530 and 500, in explicit contrast to those by SGA. More diverse suboptimal solutions were obtained than by SGA. Then, changes in index of diversity from generation to generation were examined (Figure 9). For SGA, average indexes of diversity in 32 attempts are shown. Index of diversity varied around 0.6 in island-GA or around 0.4 to 0.3 in SGA. This is because search space was larger for island-GA because the index of diversity could be maintained at a high level since it is a heterogeneous model based on the index of diversity. In SGA, convergence to a globally optimal solution occurred.

\subsubsection{Changes in fitness}

Figure 10 shows changes in average highest fitness. Plotted values in the figure are the average highest fitness in subpopulation for island-GA and the average in 32 attempts for SGA.

Similar curves are drawn in Figure 10. Thus, search process for reaching optimal solutions is also similar for island-GA and SGA. Multiple solutions were obtained in island-GA, so changes in fitness were slightly lower than in SGA.

As a result of the above discussions, it was found that heterogeneous islandGA is effective for obtaining multiple diverse practicable solutions while finding an optimal solution highly accurately.

\section{Impact resistance design for $\mathrm{RC}$ slabs by island GA}

\subsection{Outline of impact resistance design problem for RC slabs}

The authors, with a view to establishing a performance based design method for guardrails on a viaduct subjected to auto crash, have been developing a layered finite element analysis program that can evaluate the bending deflection and shear failure of reinforced concrete slabs fairly accurately [12]. The authors have also been studying impact resistance evaluation functions [13, 14].

Reinforced concrete (RC) slabs subjected to impact loads behave in a complicated manner, so fully incorporating into objective functions or restrictions the mechanical parameters, or the construction and environmental conditions that are in the mind of design engineer is difficult. Then, final decision making needs to be left to the design engineer. Presenting multiple design proposals is therefore preferable.

Here, heterogeneous island-GA is applied to impact resistance design for reinforced concrete slabs. Island-GA is compared with SGA to show the effectiveness of island-GA. SGA is executed multiple times to achieve computational complexity similar to that for island-GA.

\subsection{Outline of layered finite element method}

The layered finite element method used in this study is outlined below: Used for analysis was a layered slab model divided into layers of reinforced concrete in 
the direction of slab thickness (see Figure 11). Main and distribution reinforcements were modeled in a reinforcement layer. Thin plate bending elements were applied to each layer [12]. Impact response analysis for reinforced concrete structures generally takes much computation time. Using the analysis method adopted in this study was expected to reduce computation time considerably as compared to the case using finite element analysis with solid elements. To verify the accuracy of the analysis method used in this study, results of past impact tests were simulated. An impact test using a falling weight was conducted (Figure 12). Multiple specimens of reinforced concrete slab were made using varying concrete materials and reinforcement.

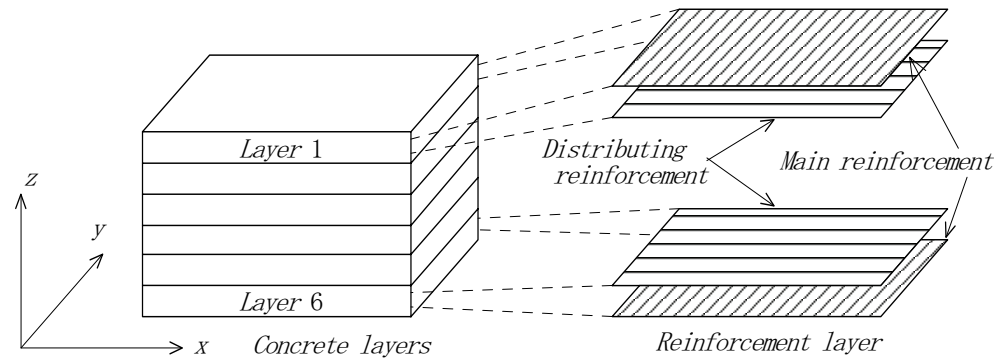

Figure 11: $\quad$ Layered slab model.

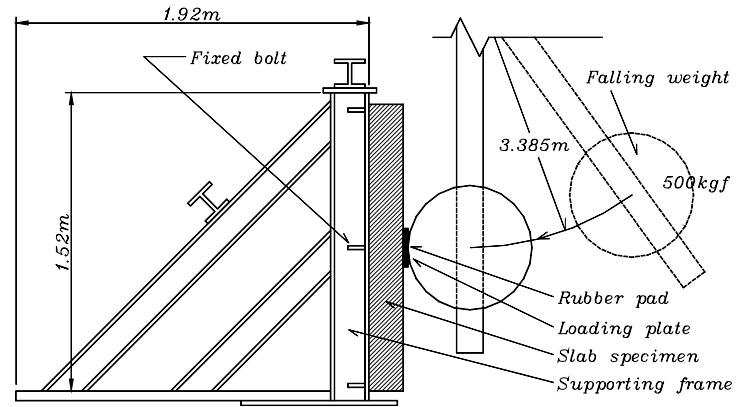

Figure 12: $\quad$ Test outline.

The reinforced concrete slab specimen $132 \mathrm{~cm}$ wide and $132 \mathrm{~cm}$ long was simply supported on two sides with a span of $120 \mathrm{~cm}$ (Figure 13). Analysis was made of a reinforced concrete slab consisting of ordinary concrete and reinforcement (SD35) to verify the accuracy of the analysis method used in this study. Figure 14 shows a layered finite element analysis model. For analysis, a quarter of actual slab was modeled. The slab was divided into six layers along its thickness, and into eleven cells each in the directions of main and distribution reinforcements. Reinforcement layers each composed of main and distribution reinforcements were inserted into two designated concrete layers. Uniformly distributed impact loads were applied to the shaded area at the center of the slab 
shown in Figure 14. An impact load-time relationship obtained in tests was input direct to the center of the analysis model. Figure 15 shows the relationship between impact load and midpoint displacement that was obtained by analysis for comparison with test results. Analysis results evidently simulated the characteristics of load-displacement history fairly well with such respects as the maximum load and softening behavior.

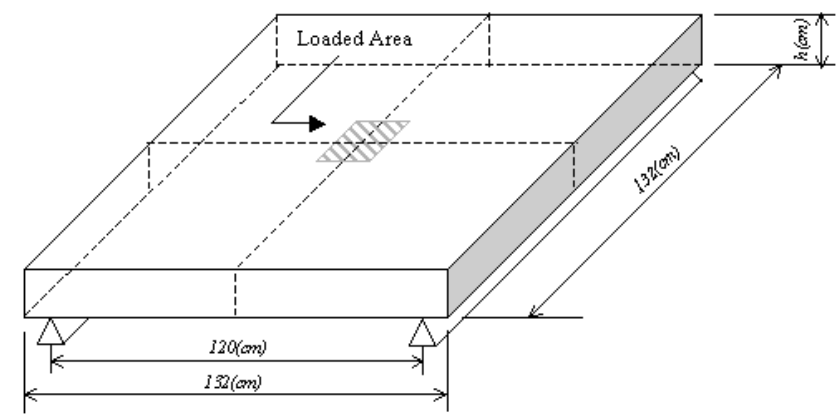

Figure 13: Reinforced concrete (RC) slab used for analysis.

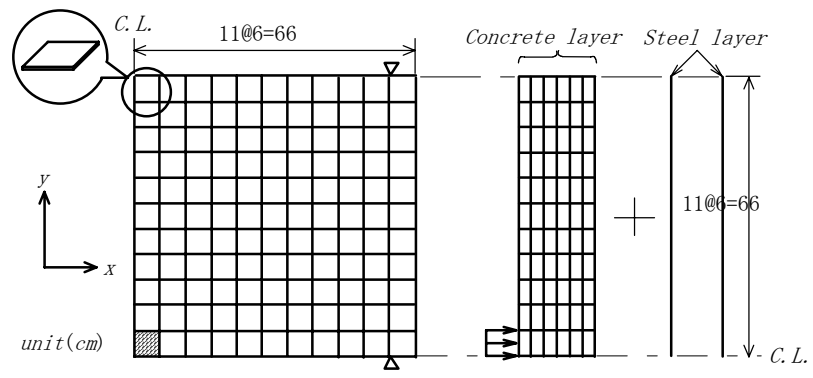

Figure 14: $\quad$ Layered finite element model (1/4 part).

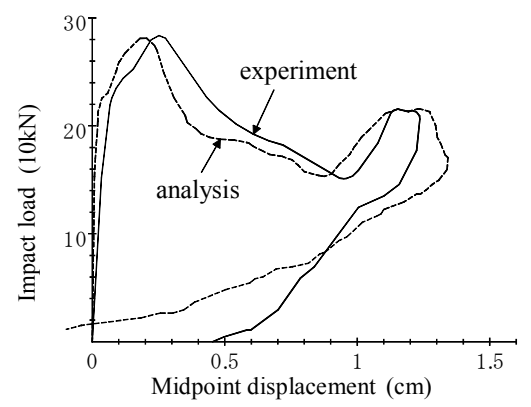

Figure 15: Impact load on reinforced concrete slab and midpoint displacement. 


\subsection{Definition of an optimization problem}

The dimensions of the concrete slab to be designed were set to be identical to those in the test. It was made possible to determine slab thickness $(h)$ according to the type of material or reinforcement used. A layer of main and distribution reinforcements was arranged in the top and bottom concrete layers. Three types of concrete were used: ordinary, high strength and steel fiber reinforced concrete. Ordinary reinforcement, high strength reinforcement, and steel fiber reinforcement (FRP) types A and B were employed. Figure 16 shows models of concrete mixes used for analysis. The relationship between the impact load input for analysis and time was represented by a triangular pulse (Figure 17). The rate of loading was fixed at $500 \mathrm{kN} / \mathrm{ms}$.

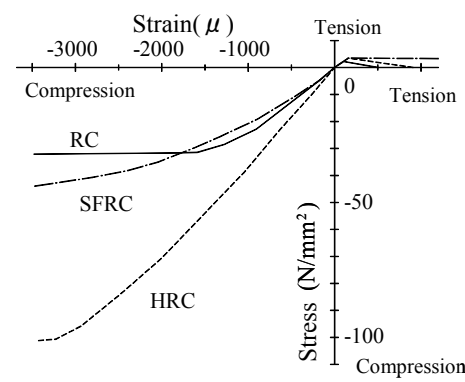

Figure 16: Stress-strain relationships for different types of concrete.

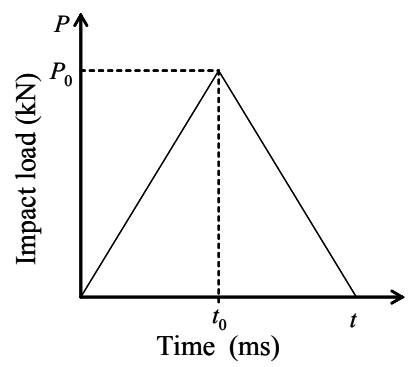

Figure 17: Triangular approximation of impact load waveform.

\subsubsection{Impact resistance evaluation indices}

The authors have proposed several impact resistance evaluation indices for reinforced concrete slabs $[13,14]$. In this study, an "impact resistance evaluation index $I_{i m p}$ " was used for evaluation, which was a combination of "local deformation index $I_{L}$ " for evaluating local deformation and "failure impact load $P_{f}$ " for evaluating the load bearing capacity of reinforced concrete slab.

4.3.1.1 Failure impact load, $\mathbf{P}_{\mathbf{f}}$ This is defined as the impact load that causes the reinforced slab to fail. The larger the failure impact load, the higher load bearing capacity the structure has.

4.3.1.2 Local deformation index, $I_{L}$ Concrete structures, when subjected to impact loading, are likely to fail while suffering from local deformation (punching shear failure). To quantitatively evaluate the local deformation, local deformation index $I_{L}$ was defined by the following equation that expressed curvature at failure, $\phi$ minus the effect of displacement at failure, $\delta_{u}$.

$$
I_{L}=\frac{\phi}{\delta_{u}}
$$


where

$$
\phi=\frac{d^{2} y}{d x^{2}}=\frac{1}{\Delta x^{2}}\left(\delta_{1}+\delta_{3}-2 \delta_{2}\right)
$$

4.3.1.3 Impact resistance evaluation index, $\mathbf{I}_{\mathrm{imp}}$ Impact resistance evaluation index $I_{\text {imp }}$ is defined to be the result of division of failure impact load $P_{f}$ by local deformation index $I_{L}$. According to the results of tests of reinforced concrete slabs, larger failure impact loads lead to greater safety against failure. At a lower local deformation index, flexural failure precedes shear failure (greater energy is absorbed). A higher impact resistance evaluation index therefore represents greater impact resistance.

$$
I_{i m p}=\frac{P_{f}}{I_{L}}
$$

\begin{tabular}{|c|c|c|}
\hline Factor & Parameter & Code \\
\hline \multirow{4}{*}{ Slab thickness } & $11.05(\mathrm{~cm})$ & 00 \\
\hline & $11.70(\mathrm{~cm})$ & 01 \\
\hline & $12.35(\mathrm{~cm})$ & 10 \\
\hline & $13.00(\mathrm{~cm})$ & 11 \\
\hline \multirow{3}{*}{ Type of concrete } & Ordinary concrete & 00 \\
\hline & High-strength concrete & 01 \\
\hline & $\begin{array}{l}\text { Steel fiber mixed } \\
\text { concrete }\end{array}$ & 10 \\
\hline \multirow{4}{*}{ Type of reinforcement } & Ordinary bars & 00 \\
\hline & High-strength bars & 01 \\
\hline & Type A FRP bars & 10 \\
\hline & Type B FRP bars & 11 \\
\hline \multirow{8}{*}{$\begin{array}{l}\text { Cross sectional area of } \\
\text { reinforcement }\end{array}$} & D6 & 000 \\
\hline & D10 & 001 \\
\hline & D13 & 010 \\
\hline & D16 & 011 \\
\hline & D19 & 100 \\
\hline & D22 & 101 \\
\hline & D25 & 110 \\
\hline & D29 & 111 \\
\hline \multirow{8}{*}{$\begin{array}{l}\text { Number of reinforcing bars } \\
\text { (a quarter section of } \\
\text { reinforced concrete slab) }\end{array}$} & 3 & 000 \\
\hline & 4 & 001 \\
\hline & 5 & 010 \\
\hline & 6 & 011 \\
\hline & 7 & 100 \\
\hline & 8 & 101 \\
\hline & 9 & 110 \\
\hline & 10 & 111 \\
\hline
\end{tabular}

Table 2: $\quad$ List of characteristics codes of reinforced concrete slab. 


\subsubsection{Coding of reinforced concrete slab characteristics and restrictions}

To apply the finite element analysis method for reinforced concrete slabs to SGA, coding the characteristics of reinforced concrete slab in a row of symbols was required for input for finite element analysis.

The genotype of individuals shown in Figure 3 was defined using binary figures. Material characteristics of reinforced concrete slab were coded as shown in Table 2. The number of characteristics parameter elements was set at a power of two inasmuch as possible. Characteristics parameter elements amounting to a number other than a power of two were all handled as lethal genes. A sample coding for a reinforced concrete slab is given in Figure 18. The following restrictions were imposed in the design problem in this study to reflect actual design methods and construction conditions.

(i) Reinforcement should be arranged at constant intervals.

(ii) The reinforcement layer should vertically consist of main, distribution, distribution and main reinforcements from the top of the slab.

(iii) Main and distribution reinforcements in a reinforcement layer should be of the same type and dimensions.

(iv) The thickness of the reinforced concrete slab should be more than $11.05 \mathrm{~cm}$ and less than $13.0 \mathrm{~cm}$.

(v) The combined total of reinforcement volume should be defined as the total amount of reinforcement, which should be less than $10,000 \mathrm{~cm}^{3}$.

(vi) The number of distribution reinforcing bars should be half the number of main reinforcing bars.

(vii) The total number of main reinforcing bars in a quarter section of the reinforced concrete slab should be 4, 6, 8 or 10 .

(viii) The upper limit of total mass of reinforced concrete slab should be $10.0 \mathrm{kN}$.

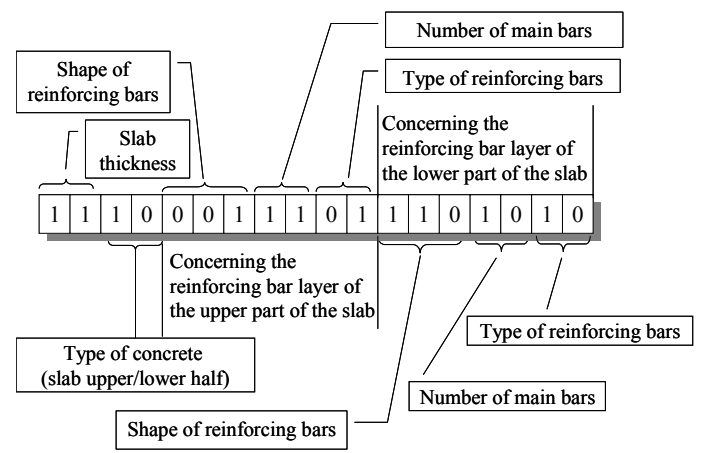

Figure 18: Sample coding for reinforced concrete slab (18 bits).

Finally, 110,592 combinations of elements $(4 \times 3 \times 6 \times 4 \times 4 \times 6 \times 4 \times 4)$ were analyzed for reinforced concrete slab under the above restrictions. To verify the validity of optimal design proposals, impact resistance evaluation index was calculated in advance by making numerical simulations for all the combinations of elements. 


\subsubsection{Integration of island-GA and FEM analysis}

To integrate island-GA and FEM analysis, fitness (impact resistance evaluation index) should be calculated by FEM analysis during genetic operator in islandGA (Figure 19). For FEM analysis, individual's genotype is converted to its phenotype as input data. FEM analysis is made based on the input data, fitness is calculated based on the analysis results, and the calculated fitness is returned to island-GA. Individuals violating restrictions are given a penalty.

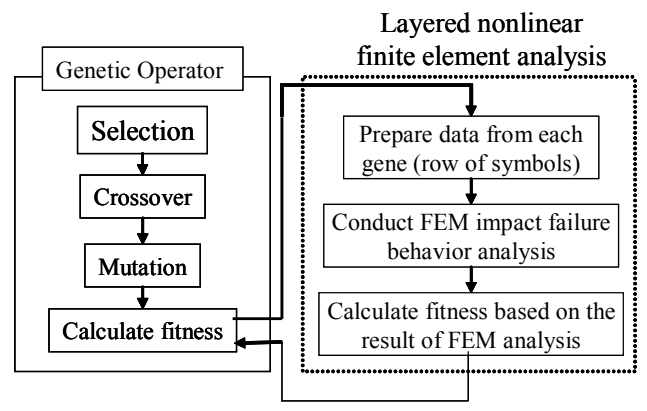

Figure 19: Genetic operator in design support system.

\subsubsection{Objective function in numerical simulation}

The objective function in numerical simulation is to maximize of Eq. (8), an impact resistance evaluation function, because the objective is to design reinforced slabs highly resistant to impact loads. Simulation conditions are listed in Table 3 as GA parameters.

Table 3: $\quad$ List of simulation conditions (GA parameters).

\begin{tabular}{|c|c|c|}
\hline & SGA & Islanad - GA \\
\hline Number of generation & \multicolumn{2}{|c|}{100} \\
\hline Number of individual & 20 & 20 \\
\hline Gene length & \multicolumn{2}{|c|}{18} \\
\hline Crossover rate & \multicolumn{2}{|c|}{$1.0^{* 1}$} \\
\hline Mutation rate & \multicolumn{2}{|c|}{$0.05^{* 1}$} \\
\hline Selection pressure & \multicolumn{2}{|c|}{$25 \%$} \\
\hline Method of selection & \multicolumn{2}{|c|}{$\begin{array}{c}\text { Roulette selection (elitist } \\
\text { strategy) }\end{array}$} \\
\hline Method of crossover & \multicolumn{2}{|c|}{ Two-point crossover } \\
\hline Number of sub population & & 32 \\
\hline Migration rate & & 0.5 \\
\hline Number of attempts & 32 & \\
\hline
\end{tabular}


Table 4: Analysis results.

\begin{tabular}{|c|c|c|c|c|c|c|c|c|c|}
\hline \multirow[b]{2}{*}{$\begin{array}{l}\text { Design } \\
\text { Plan }\end{array}$} & \multirow[b]{2}{*}{$\begin{array}{c}\text { Slab } \\
\text { thickness } \\
(\mathrm{cm})\end{array}$} & \multirow[b]{2}{*}{$\begin{array}{l}\text { Type of } \\
\text { concrete }\end{array}$} & \multicolumn{3}{|c|}{ Reinforcement in the upper part } & \multicolumn{3}{|c|}{ Reinforcement in the lower part } & \multirow{2}{*}{$\begin{array}{l}\text { Fitness Value } \\
\text { (Impact } \\
\text { resistance } \\
\text { evaluation } \\
\text { function) } \\
\end{array}$} \\
\hline & & & Shape & $\begin{array}{c}\text { Number of } \\
\text { main } \\
\text { reinforcement }\end{array}$ & Type & Shape & $\begin{array}{c}\text { Number } \\
\text { of main } \\
\text { reinforce } \\
\text { ment } \\
\end{array}$ & Type & \\
\hline 1 & 13 & $\begin{array}{l}\text { High-strength } \\
\text { concrete }\end{array}$ & D13 & 12 & $\begin{array}{c}\text { Type B fiber- } \\
\text { reinforced } \\
\text { plastic bars }\end{array}$ & D16 & 12 & $\begin{array}{c}\text { High-strength } \\
\text { bars }\end{array}$ & 1.959488 \\
\hline 2 & 13 & $\begin{array}{l}\text { High-strength } \\
\text { concrete }\end{array}$ & D13 & 20 & $\begin{array}{c}\text { Type B fiber- } \\
\text { reinforced } \\
\text { plastic bars }\end{array}$ & D13 & 16 & \begin{tabular}{|c|} 
Type B fiber- \\
reinforced \\
plastic bars
\end{tabular} & 1.948137 \\
\hline $3 \sim 6$ & 13 & $\begin{array}{l}\text { High-strength } \\
\text { concrete }\end{array}$ & D16 & 8 & ALL & D16 & 12 & $\begin{array}{c}\text { Type B fiber- } \\
\text { reinforced } \\
\text { plastic bars }\end{array}$ & 1.945316 \\
\hline $7 \sim 8$ & 13 & $\begin{array}{l}\text { High-strength } \\
\text { concrete }\end{array}$ & D13 & 12 & $\begin{array}{l}\text { High-strength } \\
\text { bars or } \\
\text { Oedinary bars }\end{array}$ & D19 & 12 & Ordinary bars & 1.938038 \\
\hline $9 \sim 10$ & 13 & $\begin{array}{l}\text { High-strength } \\
\text { concrete }\end{array}$ & D16 & 8 & \begin{tabular}{|c|} 
Type A or B \\
fiber- \\
reinforced \\
plastic bars \\
\end{tabular} & D19 & 12 & Ordinary bars & 1.938038 \\
\hline 11 & 13 & $\begin{array}{l}\text { High-strength } \\
\text { concrete }\end{array}$ & D22 & 8 & $\begin{array}{c}\text { Type A fiber- } \\
\text { reinforced } \\
\text { plastic bars }\end{array}$ & D16 & 8 & $\begin{array}{c}\text { Type A fiber- } \\
\text { reinforced } \\
\text { plastic bars }\end{array}$ & 1.924855 \\
\hline 12 & 13 & $\begin{array}{l}\text { High-strength } \\
\text { concrete }\end{array}$ & D19 & 12 & $\begin{array}{c}\text { Type B fiber- } \\
\text { reinforced } \\
\text { plastic bars } \\
\end{array}$ & D16 & 8 & $\begin{array}{c}\text { Type B fiber- } \\
\text { reinforced } \\
\text { plastic bars }\end{array}$ & 1.922138 \\
\hline $13 \sim 16$ & 13 & $\begin{array}{l}\text { High-strength } \\
\text { concrete }\end{array}$ & D13 & 8 & ALL & D16 & 20 & $\begin{array}{c}\text { Type A fiber- } \\
\text { reinforced } \\
\text { plastic bars }\end{array}$ & $\begin{array}{c}1.892857 \sim \\
1.889959\end{array}$ \\
\hline 17 & 13 & $\begin{array}{l}\text { High-strength } \\
\text { concrete }\end{array}$ & D13 & 12 & $\begin{array}{l}\text { Type B fiber- } \\
\text { reinforced } \\
\text { plastic bars }\end{array}$ & D16 & 8 & $\begin{array}{c}\text { High-strength } \\
\text { bars }\end{array}$ & 1.887584 \\
\hline 18 & 13 & $\begin{array}{l}\text { High-strength } \\
\text { concrete }\end{array}$ & D16 & 12 & \begin{tabular}{|c|} 
Type B fiber- \\
reinforced \\
plastic bars
\end{tabular} & D19 & 8 & Ordinary bars & 1.884905 \\
\hline
\end{tabular}

\subsection{Simulation results and discussions}

\subsubsection{Potential design proposals}

Table 4 lists some of the analysis results. Design proposal 1, a solution with the highest fitness (impact resistance evaluation index), the optimal solution, was obtained in $44 \%$ of subpopulations in heterogeneous island-GA, and in $38 \%$ of all rounds of calculations in SGA. For SGA, the percentage represents the number of attempts in which the optimal solution was obtained. In island-GA, migration was based on the index of diversion as proposed in this study. The optimal solution was obtained more frequently in island-GA than in SGA. Thus, calculation accuracy was higher in island-GA.

Figure 20 shows distributions of highest fitness in each subpopulation. Figures in squares $(\square)$ and diamonds $(\diamond)$ correspond to the numbers assigned to design proposals listed in Table 4. In SGA, potential solutions with a fitness of 1.96 through 1.94, or design proposals 2 and 3, were output in $53 \%$ of all rounds of calculations. It is therefore assumed that the design problem has numerous 
local solutions. Then, in SGA, convergence to a local optimal solution rather than a global optimal solution tended to occur.

In either algorithm, design proposals 1, 2, 3 and 9 were output. In heterogeneous island-GA, design proposals 7, 13, 19, 23 and 39 were additionally output.

Judging from the results described above, optimal solutions are output more accurately in heterogeneous island-GA than in SGA for problems with numerous local solutions, and numerous suboptimal solutions, or potential solutions, are output.

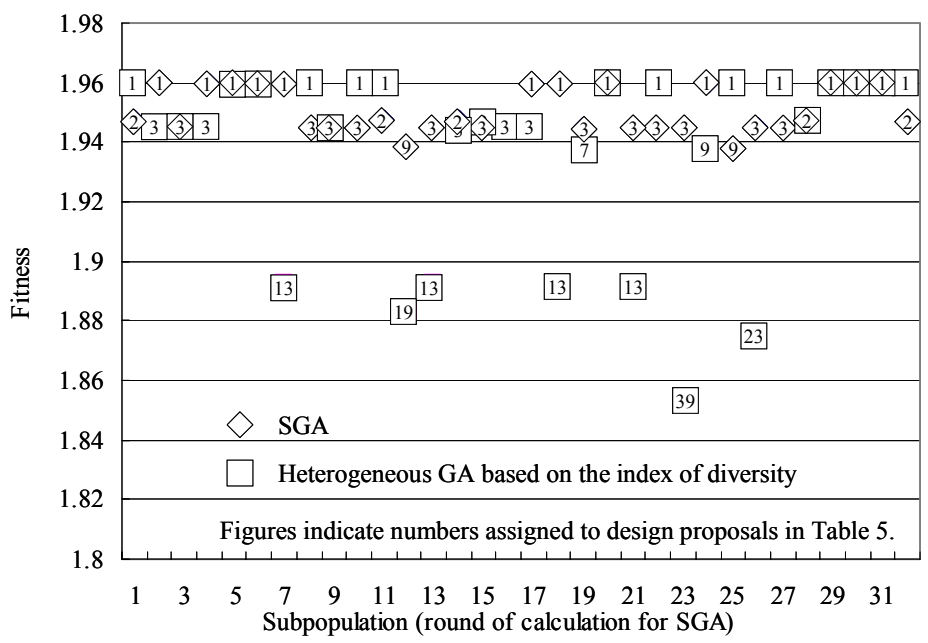

Figure 20: Distribution of potential solutions in each subpopulation (distribution of potential solutions in each round of calculation for SGA).

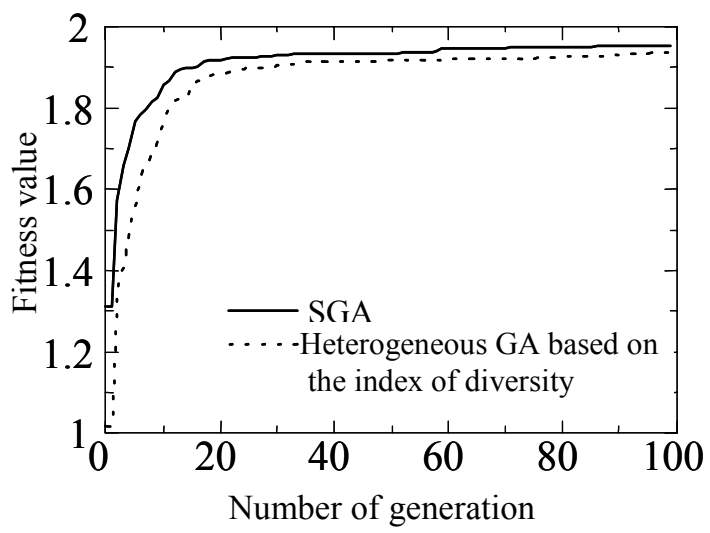

Figure 21: Changes in average highest fitness. 


\subsubsection{Changes in fitness}

Figure 21 shows changes in average highest fitness. For SGA, average in multiple rounds of calculations is indicated. In either SGA or in heterogeneous island-GA, similar curves are drawn, so the search process for obtaining an optimal solution may be the same. In heterogeneous island-GA, changes in fitness were slightly lower than in SGA. This is because average fitness among each subpopulation was used. The result is reasonable for island-GA, which produced multiple practicable solutions.

\subsubsection{Design proposals obtained}

All the design proposals obtained in heterogeneous island-GA had more reinforcement at the bottom of the slab than at the top. Concrete is generally weak in tension, so more reinforcement is arranged at the bottom of the slab that is subjected to tension.

For problems with local solutions such as the design problem in this study, heterogeneous island GA accurately provides an optimal solution even where SGA cannot ensure the identification of an optimal solution. Multiple design proposals can be obtained in heterogeneous island-GA. Thus, heterogeneous island-GA proved highly effective.

\section{Conclusions}

In this study, island-GA, a distributed-GA, was applied to a problem of impact resistance design for reinforced concrete slabs. To accurately obtain an optimal solution and deduce multiple potential design proposals, a method of migration based on the index of diversity was proposed. Island-GA was compared with SGA to verify the effectiveness of island-GA. The conclusions obtained in this study are described below:

1) A study was made of the threshold value and migration rate for a method of migration based on the index of diversity that was proposed in this study. As a result, an optimal solution was obtained and multiple suboptimal solutions were output at a threshold value of 0.1 and a migration rate of 0.5 .

2) As a result of simulation of the knapsack problem, it was found that diversity in characteristics of subpopulations was higher in heterogeneous island-GA than in SGA.

3) As a result of simulation of the knapsack problem, it was found that heterogeneous island-GA based on the index of diversity, unlike SGA that was executed multiple times in isolation, could output not only a optimal solution but also multiple suboptimal solutions.

4) Island-GA was applied to a design problem for reinforced concrete slabs subjected to impact loading. As a result, it was found that island-GA could output slightly more optimal solutions than SGA. Heterogeneous island-GA output nine design proposals. SGA, on the other hand, output four design proposals.

5) In design proposals obtained using heterogeneous island-GA, numerous reinforcing bars were arranged at the bottom of the slab. Thus, highly practicable design proposals were obtained. 


\section{References}

[1] Sugimoto, H., Yamamoto, H., Sasaki, T. and Mitsuo, A.: On design optimization of retaining wall structures by genetic algorithm, Proceedings of the Japan Society of Civil Engineers (JSCE), No. 474/VI20, pp. 105-114, Sep. 1993.

[2] Sugimoto, H., LU Bian Li and Yamamoto, H.: A study on an improvement of reliability of GA for the discrete structural optimization, Proceedings of JSCE, No. 471/I-24, pp. 67-76, July 1993.

[3] Katsuki, S., Nagao, H., Suwa, M. and Sato, H.: an application of genetic algorithm using sub-objective optimal elite operation for interactive structural optimal design, Proceedings of JSCE, No. 668/I-54, pp. 143-161, Jan. 2001.

[4] Miyamoto, A., Tei, K., Nakamura, H. and Bull, J.W.: Behavior of Prestressed Beam Strengthened with External Tendons, Journal of Structural Engineering (ASCE), Vol. 126, No. 9, pp.1033-1044, 2000.9.

[5] Sterling, T.L., Salmon, J., Becker, D.J. and Savarese, D.F.: How to Build a Beowulf: A Guide to the Implementation and Application of PC Clusters, Sangyotosho Publishing, March 2001.

[6] Fujitsu: Press release: http://pr.fujitsu.com/jp/news/2005/11/7.html.

[7] Gordon, V.S. and Whitley, D.Serial and Parallel Genetic Algorithms as Function Optimizers, Technical Report CS-93-114, Sep. 1993.

[8] Mitsubishi Research Institute Inc. Parallel genetic algorithm, http://web. yl.is.s.u-tokyo.ac.jp/pl/abclf/ipa-final/reports/html/5/4/5-4.html,Feb. 1997.

[9] Kaneyasu, T., Miki, M. and Sano, M.: Search mechanism of Distributed Genetic Algorithm, IPSJ Symposium Series, Vol. 2001, No. 12, pp. 339-342, Dec. 2001.

[10] Miki, M., Kaneyasu, T., Hatanaka, K. and Yoshida, J.: Effectiveness of parallel distributed genetic algorithm, Japan Society for Computational Engineering and Science, Paper No. 20000038. Aug. 2000.

[11] Mori, K., Tsukiyama, M. and Fukuda, T.: Proposal of a diverse immunological algorithm and its application to load allocation problems, Journal of Electrical Engineering C, Vol. 113, No. 10, 1993.

[12] King, M.W., Miyamoto, A. and Nshimura, A.: Failure Criteria and Failure modes for Concrete slabs under impulsive loads, Mem.Grad.School Sci. \& Technol., Kobe Univ., 9-A, 1991.

[13] Miyamoto, A., Mito, M. and Kitayama, A.: Evaluation of impact characteristics and impact resistance of layered concrete slabs, JSCE Journal of Structural Engineering, Vol. 41A, pp. 1277-1288, March 1995.

[14] Emoto, H., Nakamura, H. and Miyamoto, A.: A study on the development of impact resistance design support for reinforced concrete slabs using GA, JSCE Journal of Structural Engineering, Vol. 45A, pp. 453-464, March 1999. 